\title{
Pelabelan Harmonis Ganjil pada Kelas Graf Baru Hasil Operasi Cartesian Product
}

\author{
Fery Firmansah $^{1}$, Muhammad Ridlo Yuwono ${ }^{2}$ \\ Pend. Matematika, Universitas Widya Dharma Klaten ${ }^{1}$, fery.firmansah004@gmail.com ${ }^{1}$ \\ Pend. Matematika, Universitas Widya Dharma Klaten ${ }^{2}$, ridloyuwono90@gmail.com²
}

DOI:https://doi.org/10.15642/mantik.2017.3.2.87-95

\begin{abstract}
Abstrak
Kelas graf yang mempunyai sifat pelabelan harmonis ganjil disebut sebagai graf harmonis ganjil. Graf jaring adalah graf yang diperoleh dari operasi cartesian product dari dua graf lintasan. Kontruksi graf ular jaring terinspirasi dari definisi graf ular dengan mengganti graf lingkaran dengan graf jaring. Pada makalah ini akan ditunjukkan bahwa graf ular jaring memenuhi sifat pelabelan harmonis ganjil sedemikian sehingga graf ular jaring adalah graf harmonis ganjil. Pada bagian akhir akan ditunjukkan juga bahwa gabungan graf ular jaring merupakan graf harmonis ganjil.
\end{abstract}

Kata kunci: cartesian product, gabungan graf, graf harmonis ganjil, graf ular jaring

\begin{abstract}
Graph class which has the characteristic of odd harmonious labeling is called as odd harmonious graph. Net graph is a graph which is gained by using operation Cartesian product of two line graphs. The construction of snake-net graph is inspired by the definition of snake graph replacing the round graph to net graph. In this paper, the study will show that snake-net graph fulfill the characteristic of odd harmonious graph in such a way snake-net graph is the odd harmonious graph. In the end of this paper, it is also shown that the union of snake-net graph is also called as the odd harmonious graph.
\end{abstract}

Keywords: Cartesian product, union graph, odd harmonious graph, snake-net graph

\section{Pendahuluan}

Pelabelan graf merupakan salah satu topik dari matematika kombinatorik yang berkembang sangat pesat akhir-akhir ini. Selain berkembang secara teori, pelabelan graf juga telah banyak diaplikasikan dalam berbagai bidang keilmuan. Pada mulanya pelabelan graf diperkenalkan oleh Sedlacek tahun 1963 yang terinspirasi dari kasus bujur sangkar ajaib yang disebut pelabelan ajaib. Rosa tahun 1970, menulis makalah tentang pelabelan graceful yang digunakan untuk menyelesaikan kasus dekomposisi dari graf lengkap. Sampai tahun 2016, hasil tentang penelitian pelabelan graf sudah banyak dipubliksikan dalam berbagai jurnal dan makalah yang dikumpulkan dan diperbaharui secara teratur oleh Gallian. Gallian (2016) telah merangkum kurang lebih 2000 jurnal pelabelan graf dari seluruh peneliti dunia dan dari 2000 jurnal tersebut diperoleh kurang lebih 200 kelas graf baru beserta pelabelannya.

Selain pelabelan ajaib dan pelabelan graceful, masih terdapat terdapat jenis pelabelan yang lain diantaranya adalah pelabelan harmonis yang 
diperkenalkan oleh Graham dan Sloane pada tahun 1980 dan pelabelan harmonis ganjil yang diperkenalkan oleh Liang dan Bai pada tahun 2009. Liang dan Bai [10] telah menunjukkan sifat-sifat khusus yang dimiliki oleh graf harmonis ganjil, serta beberapa kelas graf yang memenuhi pelabelan harmonis ganjil. Hasil penelitian yang relevan dengan penelitian ini diantaranya dapat dilihat di Abdel-Aal [1]; Alyani, et. al. [2]; Firmansah \& Sugeng [3]; Firmansah [4]; Firmansah \& Syaifuddin [5]; Firmansah \& Yuwono [6]; Jeyanthi dan Philo [7], Jeyanthi, et. al. [8], Saputri et. al. [11]; dan Vaidya \& Shah [12].

Pada makalah ini akan diberikan kontruksi kelas graf baru hasil operasi cartesian product dari graf lintasan $P_{m}$ dan $P_{n}$ yaitu graf jaring $L_{m, n}=$ $P_{m} \times P_{n}$. Untuk $m=n=3$ diperoleh graf jaring $L_{3,3}$ yang akan membentuk graf ular jaring $k L_{3,3}$. Selanjutnya akan dibuktikan bahwa graf ular jaring $k L_{3,3}$ memenuhi sifat-sifat pelabelan harmonis ganjil sehingga graf ular jaring $k L_{3,3}$ adalah keluarga baru dari graf harmonis ganjil. Dibagian akhir akan ditunjukkan bahwa gabungan graf ular jaring $k L_{3,3} \cup k L_{3,3}$ juga merupakan keluarga dari graf harmonis ganjil.

\section{Kajian Teori}

Misalkan $\mathbb{Z}_{n}$ adalah himpunan bilangan bulat modulo $n$. Simbol $[a, b]$ didefinsikan oleh $\{x \mid x \in \mathbb{Z}, a \leq x \leq b\}$ dan $[a, b]_{d}$ didefinsikan oleh $\{x \mid x \in \mathbb{Z}, a \leq x \leq b, x \equiv a(\bmod d)\}$.

Graf $G(p, q)$ adalah graf $G$ dengan order $p=$ $|V(G)|$ simpul dan size $q=|E(G)|$ busur.

Definisi 2.1 [9] Graf $G(p, q)$ dikatakan graf harmonis jika terdapat fungsi injektif $f: V(G) \rightarrow Z_{q}$ sedemikian sehingga menginduksi $f^{*}: E(G) \rightarrow \mathbb{Z}_{q}$ yang didefinisikan oleh $f^{*}(u v)=(f(u)+$ $f(v))(\bmod q)$ yang bersifat bijektif, dan $f$ adalah pelabelan harmonis dari graf $G(p, q)$.

Definisi 2.2 [10] Graf $G(p, q)$ dikatakan graf harmonis ganjil jika terdapat fungsi injektif $f: V(G) \rightarrow[0,2 q-1]=\{0,1,2,3, \ldots, 2 q-1\}$

sedemikian sehingga menginduksi fungsi $f^{*}: E(G) \rightarrow[1,2 q-1]_{2}=\{1,3,5,7, \ldots, 2 q-1\}$ yang didefinisikan oleh $f^{*}(u v)=f(u)+f(v)$ yang bersifat bijektif, dan $f$ adalah pelabelan harmonis ganjil dari graf $G(p, q)$.

Definisi 2.3 [10] Graf ular $k C_{4}$ dengan $k \geq 1$ adalah graf terhubung dengan $k$ blok yang memiliki titik potong blok berupa lintasan dan setiap $k$ blok isomorfik dengan graf ular $C_{4}$

\section{Hasil Penelitian dan Pembahasan}

\subsection{Pelabelan Harmonis Ganjil pada Graf Ular Jaring}

Pada bagian ini diberikan definisi dari graf ular jaring $k L_{3,3}$ yang terinspirasi dari graf ular $k C_{4}$ yaitu dengan mengganti graf lingkaran $C_{4}$ dengan graf jaring $L_{3,3}$.

Definisi 3.1 Graf ular jaring $k L_{3,3}$ dengan $k \geq 1$ adalah graf terhubung dengan $k$ blok yang memiliki titik potong blok berupa lintasan dan setiap $k$ blok isomorfik dengan graf jaring $L_{3,3}$.

Berikut pada Gambar 1 diberikan notasi simpul, notasi busur dan kontruksi dari graf ular jaring $k L_{3,3}$ dengan $k \geq 1$. 


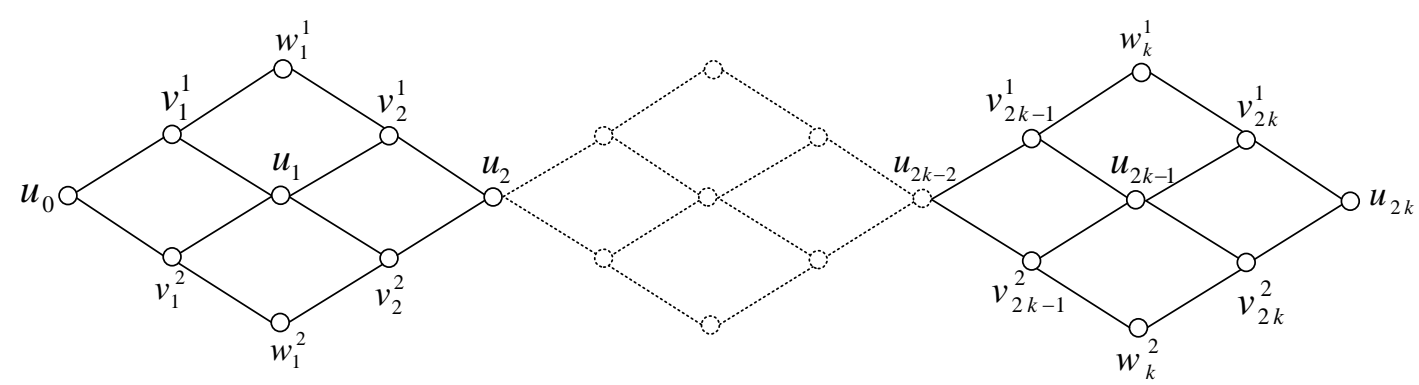

Gambar 1 Notasi simpul, notasi busur dan kontruksi dari graf ular jaring $k L_{3,3}$

Berdasarkan kontruksi pada Gambar 1 diperoleh definisi himpunan simpul dan himpunan busur dari graf ular jaring $k L_{3,3}$ dengan $k \geq 1$ sebagai berikut:

$$
\begin{aligned}
& V\left(k L_{3,3}\right)=\left\{u_{i} \mid 0 \leq i \leq 2 k\right\} \cup \\
& \left\{v_{i}^{j} \mid 1 \leq i \leq 2 k, j=1,2\right\} \cup \\
& \left\{w_{i}{ }^{j} \mid 1 \leq i \leq k, j=1,2\right\} \text { dan } \\
& E\left(k L_{3,3}\right)=\left\{u_{i} v_{(i+1)}{ }^{j} \mid 0 \leq i \leq 2 k-1, j=1,2\right\} \\
& \cup\left\{v_{i}^{j} u_{i} \mid 1 \leq i \leq 2 k, j=1,2\right\} \\
& \cup\left\{v_{(2 i-1)}{ }^{j} w_{i}^{j} \mid 1 \leq i \leq k, j=1,2\right\} \\
& \cup\left\{w_{i}^{j} v_{(2 i)}^{j} \mid 1 \leq i \leq k, j=1,2\right\}
\end{aligned}
$$

Selanjutnya diberikan sifat yang menyatakan bahwa graf ular jaring $k L_{3,3}$ dengan $k \geq 1$ adalah graf harmonis ganjil yang dinyatakan dalam Teorema 3.2.

Teorema 3.2 Graf ular jaring $k L_{3,3}$ dengan $k \geq 1$ adalah graf harmonis ganjil.

\section{BUKTI.}

Berdasarkan himpunan himpunan simpul dan himpunan busur dari graf ular jaring $k L_{3,3}$ dengan $k \geq 1$ diperoleh order $p=\left|V\left(k L_{3,3}\right)\right|=$ $9 k-1$ dan size $q=\left|E\left(k L_{3,3}\right)\right|=12 k$.

Berikut didefinisikan fungsi pelabelan simpul $f: V\left(k L_{3,3}\right) \rightarrow\{0,1,2,3 \ldots, 24 k-1\}$

$f\left(u_{i}\right)=4 i, 0 \leq i \leq 2 k$

$f\left(v_{i}^{j}\right)=4 i+2 j-5,1 \leq i \leq 2 k, j=1,2$

$f\left(w_{i}^{j}\right)=24 k-16 i-4 j+14$,

$$
1 \leq i \leq k, j=1,2
$$

Berdasarkan fungsi pelabelan simpul $f$ pada persamaan (1.1), (1.2), dan (1.3) diperoleh himpunan simpul $f\left(V\left(k L_{3,3}\right)\right)$ setelah dilabel sebagai berikut.

$$
\begin{gathered}
f\left(V\left(k L_{3,3}\right)\right)=\{0,4,8,12, \ldots, 8 k\} \\
\cup\{1,5,9, \ldots, 8 k-3,3,7,11, \ldots, 8 k \\
-1\} \\
\cup\left\{\begin{array}{c}
24 k-6,24 k-22,24 k-38, \ldots, 8 k+10, \\
24 k-10,24 k-26,24 k-42, \ldots, 8 k+6
\end{array}\right\} \\
=\{0,1,3,4,5,7,8,9,11, \ldots, 8 k-3,8 k-1,8 k, 8 k \\
\quad+6,8 k+10, \ldots, 24 k-10,24 k-6\} \\
=\{0,1,3,4, \ldots, 24 k-6\}
\end{gathered}
$$

Terlihat bahwa fungsi pelabelan simpul $f$ memberikan label yang berbeda pada setiap simpul dan memenuhi $f\left(V\left(k L_{3,3}\right)\right)=\{0,1,3,4, \ldots, 24 k-$ $6\} \subseteq\{0,1,2,3 \ldots, 24 k-1\} \quad$ sedemikian sehingga fungsi pelabelan simpul $f$ memenuhi sifat pemetaan injektif.

Langkah selanjutnya akan ditunjukan bahwa fungsi pelabelan busur $f^{*}$ memenuhi sifat pemetaan bijektif. Berdasarkan definisi $f^{*}(u v)=f(u)+$ $f(v)$ maka fungsi pelabelan simpul $f$ akan menginduksi pelabelan busur $f^{*}: E\left(k L_{3,3}\right) \rightarrow$ $\{1,3,5,7, \ldots, 24 k-1\}$, sehingga didapatkan kontruksi fungsi pelabelan busur $f^{*}$ sebagai berikut: $f^{*}\left(u_{i} v_{(i+1)}^{j}\right)=8 i+2 j-1$,

$$
0 \leq i \leq 2 k-1, j=1,2
$$

$f^{*}\left(v_{i}^{j} u_{i}\right)=8 i+2 j-5$,

$$
1 \leq i \leq 2 k, j=1,2
$$

$$
f^{*}\left(v_{(2 i-1)}^{j} w_{i}^{j}\right)=24 k-8 i-2 j+5 \text {, }
$$$$
1 \leq i \leq k, j=1,2
$$

$$
\begin{gathered}
f^{*}\left(w_{i}^{j} v_{(2 i)}^{j}\right)=24 k-8 i-2 j+9, \\
1 \leq i \leq k, j=1,2
\end{gathered}
$$

Berdasarkan fungsi pelabelan busur $f^{*}$ pada persamaan (1.4), (1.5), (1.6) dan (1.7) diperoleh himpunan busur $f^{*}\left(E\left(k L_{3,3}\right)\right)$ setelah dilabel sebagai berikut; 
$f^{*}\left(E\left(k L_{3,3}\right)\right)=\{1,9,17,25, \ldots, 16 k-7,3,11,19,27, \ldots, 16 k-5\}$

$\cup\{5,13,21,29, \ldots, 16 k-3,7,15,23,31, \ldots, 16 k-1\}$

$\cup\left\{\begin{array}{l}24 k-5,24 k-13,24 k-21,24 k-29, \ldots, 16 k+3, \\ 24 k-7,24 k-15,24 k-23,24 k-31, \ldots, 16 k+1\end{array}\right\}$

$\cup\left\{\begin{array}{l}24 k-1,24 k-9,24 k-17,24 k-25, \ldots, 16 k+7, \\ 24 k-3,24 k-11,24 k-19,24 k-27, \ldots, 16 k+5\end{array}\right\}$

$=\left\{\begin{array}{c}1,3,5,7,9,13,15,17,19,21,23,25,27,29, \ldots, 16 k-7,16 k-5,16 k-3,16 k-1 \\ 16 k+1,16 k+3,6 k+5,16 k+7, \ldots, 24 k-31,24 k-29,24 k-27,24 k-25, \\ 24 k-23,24 k-21,24 k-19,24 k-17,24 k-15,24 k-13,24 k-11,24 k-9, \\ 24 k-7,24 k-5,24 k-3,24 k-1\end{array}\right\}$

$=\{1,3,5,7, \ldots, 24 k-1\}$.

Terlihat bahwa fungsi pelabelan busur $f^{*}$ memberikan label yang berbeda pada setiap busur dan

$$
f^{*}\left(E\left(k L_{3,3}\right)\right)=\{1,3,5,7, \ldots, 24 k-1\}
$$

sedemikian sehingga fungsi pelabelan busur $f^{*}$ memenuhi sifat pemetaan bijektif. Akibatnya graf

ular jaring $k L_{3,3}$ dengan $k \geq 1$ adalah graf harmonis ganjil.

Contoh 3.3 Diberikan contoh pelabelan harmonis ganjil pada graf ular jaring $7 L_{3,3}$ pada Gambar 2 .

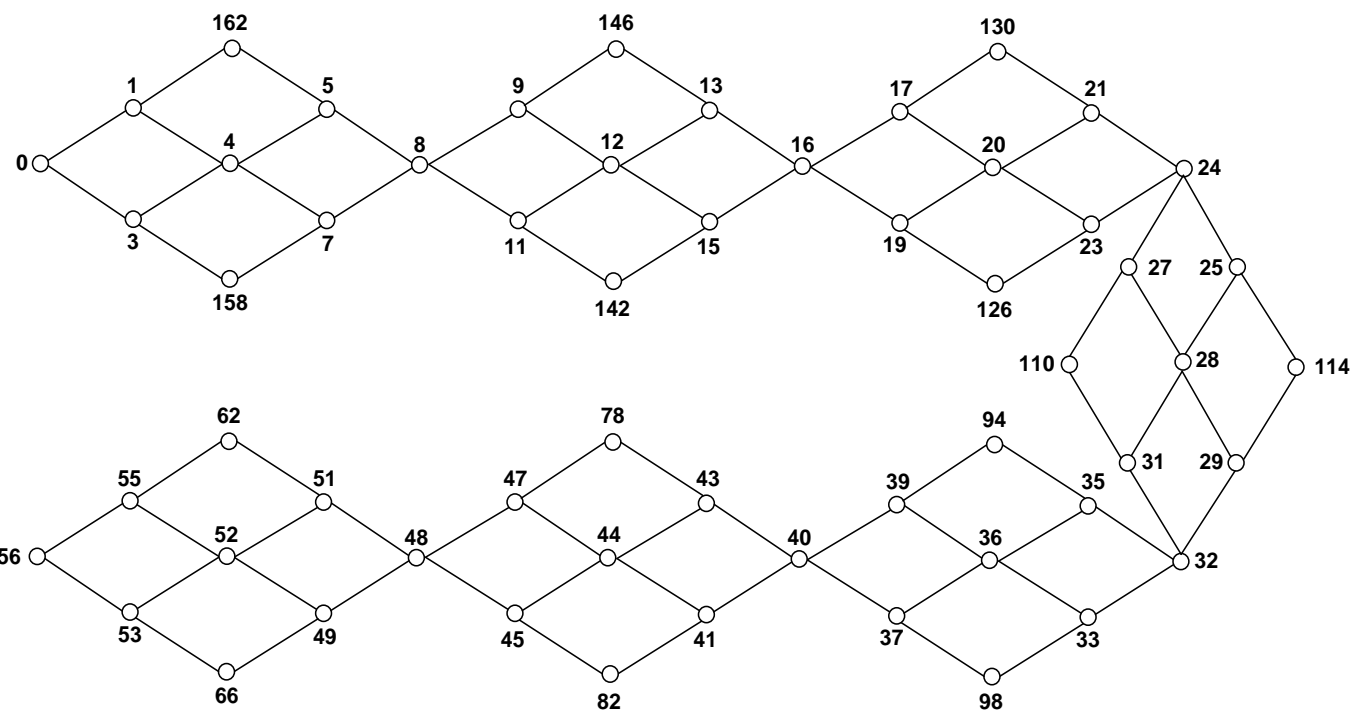

Gambar 2 Pelabelan harmonis ganjil pada graf ular jaring $7 L_{3,3}$

\subsection{Pelabelan Harmonis Ganjil pad Gabungan Graf Ular Jaring}

Hasil penelitian selanjutnya adalah pelabelan harmonis ganjil pada gabungan graf ular jaring $k L_{3,3} \cup k L_{3,3}$ dengan $k \geq 1$. Berikut diberikan definisi dari gabungan graf ular jaring $k L_{3,3} \cup k L_{3,3}$ dengan $k \geq 1$ yang dinyatakan dalam Definisi 3.4. 

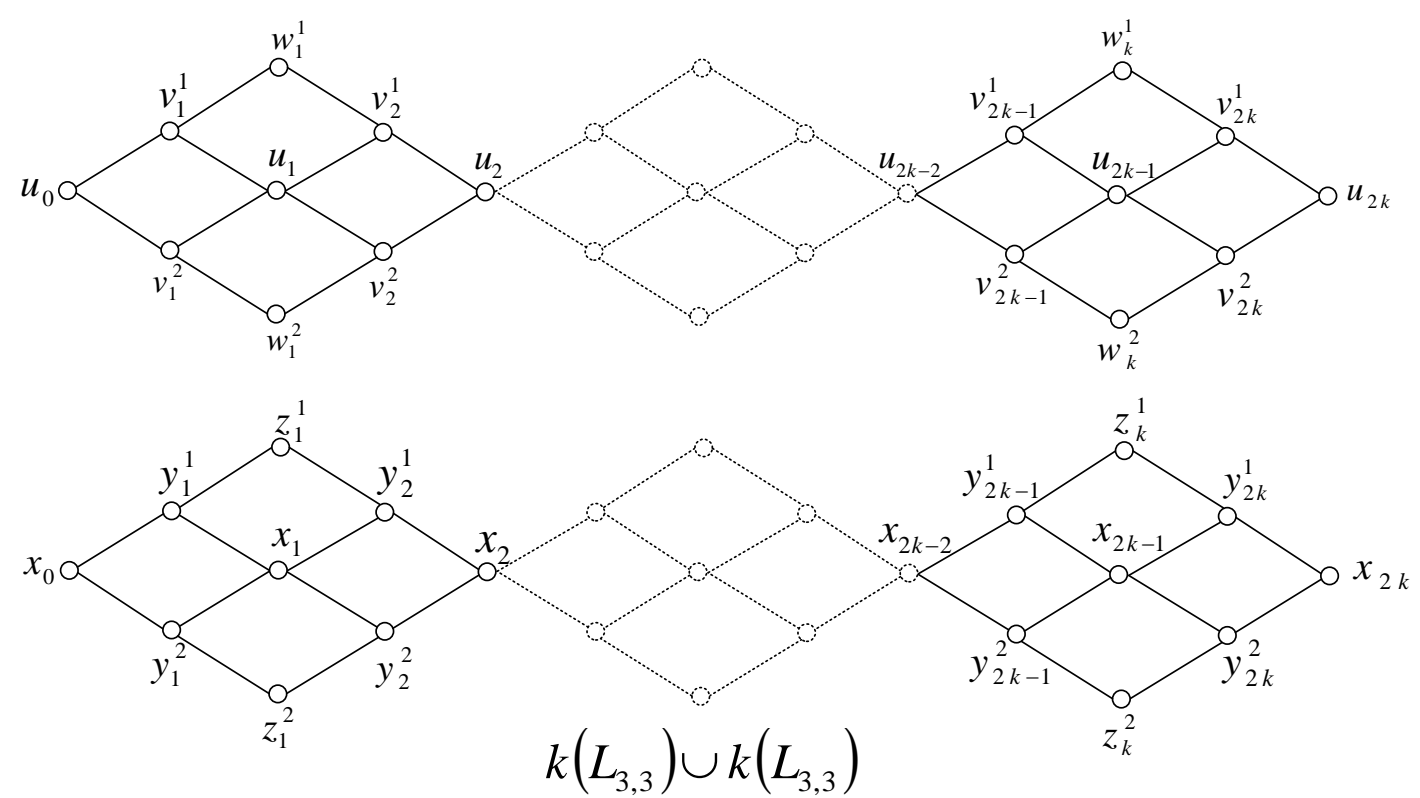

Gambar 3 Notasi simpul, notasi busur dan kontruksi dari gabungan graf ular jaring $k L_{3,3} \cup k L_{3,3}$

Berdasarkan kontruksi pada Gambar 4, busur dari gabungan graf ular jaring $k L_{3,3} \cup k L_{3,3}$ diperoleh definisi himpunan simpul dan himpunan dengan $k \geq 1$ sebagai berikut.

$$
\begin{aligned}
& V\left(k L_{3,3} \cup k L_{3,3}\right)=\left\{u_{i} \mid 0 \leq i \leq 2 k\right\} \cup\left\{v_{i}{ }^{j} \mid 1 \leq i \leq 2 k, j=1,2\right\} \cup\left\{w_{i}{ }^{j} \mid 1 \leq i \leq k, j=1,2\right\} \cup \\
& \left\{x_{i} \mid 0 \leq i \leq 2 k\right\} \cup\left\{y_{i}{ }^{j} \mid 1 \leq i \leq 2 k, j=1,2\right\} \cup\left\{z_{i}{ }^{j} \mid 1 \leq i \leq k, j=1,2\right\} \text { dan } \\
& E\left(k L_{3,3} \cup k L_{3,3}\right)=\left\{u_{i} v_{(i+1)}{ }^{j} \mid 0 \leq i \leq 2 k-1, j=1,2\right\} \cup\left\{v_{i}{ }^{j} u_{i} \mid 1 \leq i \leq 2 k, j=1,2\right\} \cup \\
& \left\{v_{(2 i-1)}{ }^{j} w_{i}^{j} \mid 1 \leq i \leq k, j=1,2\right\} \cup\left\{w_{i}{ }^{j} v_{(2 i)}^{j} \mid 1 \leq i \leq k, j=1,2\right\} \cup\left\{x_{i} y_{(i+1)}{ }^{j} \mid 0 \leq i \leq 2 k-1, j=1,2\right\} \cup \\
& \left\{y_{i}{ }^{j} x_{i} \mid 1 \leq i \leq 2 k, j=1,2\right\} \cup\left\{y_{(2 i-1)}{ }^{j} z_{i}^{j} \mid 1 \leq i \leq k, j=1,2\right\} \cup\left\{z_{i}^{j} y_{(2 i)}^{j} \mid 1 \leq i \leq k, j=1,2\right\} .
\end{aligned}
$$

Pada Teorema 3.2 diperoleh bahwa graf ular jaring $k L_{3,3}$ dengan $k \geq 1$ adalah graf harmonis ganjil, maka berikut diberikan sifat yang menyatakan bahwa gabungan graf ular jaring $k L_{3,3} \cup k L_{3,3}$ dengan $k \geq 1$ memenuhi fungsi pelabelan harmonis ganjil sedemikian sehingga gabungan graf ular jaring $k L_{3,3} \cup k L_{3,3}$ dengan $k \geq$ 1 adalah graf harmonis ganjil.

\section{Teorema 3.5}

Gabungan graf ular jaring $k L_{3,3} \cup k L_{3,3}$ dengan $k \geq 1$ adalah graf harmonis ganjil.

\section{BUKTI.}

Berdasarkan himpunan himpunan simpul dan himpunan busur dari gabungan graf ular jaring $k L_{3,3} \cup k L_{3,3}$ dengan $k \geq 1$ diperoleh order $p=$ $\left|V\left(k L_{3,3} \cup k L_{3,3}\right)\right|=18 k-2$ dan size $q=\left|E\left(k L_{3,3} \cup k L_{3,3}\right)\right|=24 k$.

Berikut didefinisikan fungsi pelabelan simpul $f: V\left(k L_{3,3} \cup k L_{3,3}\right) \rightarrow\{0,1,2,3 \ldots, 48 k-1\}$

$f\left(u_{i}\right)=4 i, 0 \leq i \leq 2 k$

$f\left(v_{i}{ }^{j}\right)=4 i+2 j-5,1 \leq i \leq 2 k, j=1,2$

$f\left(w_{i}{ }^{j}\right)=24 k-16 i-4 j+14$,

$$
1 \leq i \leq k, j=1,2
$$

$f\left(x_{i}\right)=4 i+2,0 \leq i \leq 2 k$

$f\left(y_{i}^{j}\right)=24 k+4 i+2 j-7$,

$$
\begin{array}{r}
1 \leq i \leq 2 k, j=1,2 \\
f\left(z_{i}{ }^{j}\right)=24 k-16 i-4 j+16, \\
1 \leq i \leq k, j=1,2
\end{array}
$$

Berdasarkan fungsi pelabelan simpul $f$ pada persamaan (2.1), (2.2), (2.3), (2.4), (2.5), dan (2.6) 
diperoleh himpunan simpul $f\left(V\left(k L_{3,3} \cup k L_{3,3}\right)\right)$ setelah dilabel sebagai berikut.

$f\left(V\left(k L_{3,3} \cup k L_{3,3}\right)\right)=\{0,4,8,12, \ldots, 8 k\} \cup\{1,5,9, \ldots, 8 k-3,3,7,11, \ldots, 8 k-1\}$

$\cup\left\{\begin{array}{l}24 k-6,24 k-22,24 k-38, \ldots, 8 k+10, \\ 24 k-10,24 k-26,24 k-42, \ldots, 8 k+6\end{array}\right\}$

$\cup\{2,6,10,14, \ldots, 8 k+2\}$

$\cup\left\{\begin{array}{l}24 k-1,24 k+3,24 k+7,24 k+11, \ldots, 32 k-5 \\ 24 k+1,24 k+5,24 k+9,24 k+13, \ldots, 32 k-3\end{array}\right\}$

$\cup\left\{\begin{array}{c}24 k-4,24 k-20,24 k-36,24 k-52, \ldots, 8 k+12 \\ 24 k-8,24 k-24,24 k-40,24 k-56, \ldots, 8 k+8\end{array}\right\}$

$=\left\{\begin{array}{l}0,1,2,3,4,5,6,7,8,9, \ldots, 8 k-3,8 k-1,8 k, 8 k+2,8 k+6,8 k+8,8 k+10, \ldots, \\ 24 k-10,24 k-8,24 k-6,24 k-4,24 k-1,24 k+1, \ldots, 32 k-5,32 k-3\end{array}\right\}$

$=\{0,1,2,3,4, \ldots, 32 k-3\}$

Terlihat bahwa fungsi $f$ memberikan label yang berbeda pada setiap simpul dan $f\left(V\left(k L_{3,3} \mathrm{U}\right.\right.$ $\left.\left.k L_{3,3}\right)\right)=\{0,1,2,3,4, \ldots, 32 k-3\} \subseteq$ $\{0,1,2,3 \ldots, 48 k-1\}$ sedemikian sehingga fungsi pelabelan simpul $f$ memenuhi sifat pemetaan injektif.

Setelah menunjukan fungsi pelabelan simpul $f$ memenuhi pemetaan injektif, selanjutnya akan ditunjukan bahwa fungsi pelabelan busur $f^{*}$ memenuhi pemetaan bijektif. Fungsi pelabelan $f$ akan menginduksi pelabelan $f^{*}: E\left(k L_{3,3} \cup\right.$ $\left.k L_{3,3}\right) \rightarrow\{1,3,5,7, \ldots, 48 k-1\}$ yang diperoleh dari $f^{*}(u v)=f(u)+f(v)$, sehingga didapatkan fungsi pelabelan busur sebagai berikut:

$$
\begin{aligned}
& f^{*}\left(u_{i} v_{(i+1)}^{j}\right)=8 i+2 j-1,0 \leq i \leq 2 k-1, j=1,2 \\
& f^{*}\left(v_{i}{ }^{j} u_{i}\right)=8 i+2 j-5,1 \leq i \leq 2 k, j=1,2 \\
& f^{*}\left(v_{(2 i-1)}^{j} w_{i}^{j}\right)=24 k-8 i-2 j+5,1 \leq i \leq k, j=1,2 \\
& f^{*}\left(w_{i}^{j} v_{(2 i)}^{j}\right)=24 k-8 i-2 j+9,1 \leq i \leq k, j=1,2 \\
& f^{*}\left(x_{i} y_{(i+1)}^{j}\right)=24 k+8 i+2 j-1,0 \leq i \leq 2 k-1, j=1,2 \\
& f^{*}\left(y_{i}^{j} x_{i}\right)=24 k+8 i+2 j-5,1 \leq i \leq 2 k, j=1,2 \\
& f^{*}\left(y_{(2 i-1)}^{j} z_{i}^{j}\right)=48 k-8 i-2 j+5,1 \leq i \leq k, j=1,2 \\
& f^{*}\left(z_{i}{ }^{j} y_{(2 i)}^{j}\right)=48 k-8 i-2 j+9,1 \leq i \leq k, j=1,2
\end{aligned}
$$

Berdasarkan fungsi pelabelan busur $f^{*}$ pada persamaan (2.7), (2.8), (2.9), (2.10), (2.11), (2.12), (2.13) dan (2.14) diperoleh himpunan busur $f^{*}\left(E\left(k L_{3,3} \cup k L_{3,3}\right)\right)$ setelah dilabel sebagai berikut.

$$
\begin{aligned}
& f^{*}\left(E\left(k L_{3,3} \cup k L_{3,3}\right)\right)=\{1,9,17,25, \ldots, 16 k-7,3,11,19,27, \ldots, 16 k-5\} \\
& \cup\{5,13,21,29, \ldots, 16 k-3,7,15,23,31, \ldots, 16 k-1\} \\
& \cup\left\{\begin{array}{l}
24 k-5,24 k-13,24 k-21,24 k-29, \ldots, 16 k+3, \\
24 k-7,24 k-15,24 k-23,24 k-31, \ldots, 16 k+1
\end{array}\right\} \\
& \cup\left\{\begin{array}{c}
24 k-1,24 k-9,24 k-17,24 k-25, \ldots, 16 k+7, \\
24 k-3,24 k-11,24 k-19,24 k-27, \ldots, 16 k+5
\end{array}\right\} \\
& \cup\left\{\begin{array}{c}
24 k+1,24 k+9,24 k+17,24 k+25, \ldots, 40 k-7, \\
24 k+3,24 k+11,24 k+19,24 k+27, \ldots, 40 k-5
\end{array}\right\}
\end{aligned}
$$




$$
\begin{aligned}
& \cup\left\{\begin{array}{c}
24 k+5,24 k+13,24 k+21,24 k+29, \ldots, 40 k-3, \\
24 k+7,24 k+15,24 k+23,24 k+31, \ldots, 40 k-1
\end{array}\right\} \\
& \cup\left\{\begin{array}{c}
48 k-5,48 k-13,48 k-21,48 k-29, \ldots, 40 k+3, \\
48 k-7,48 k-15,48 k-23,48 k-31, \ldots, 40 k+1
\end{array}\right\} \\
& \cup\left\{\begin{array}{c}
48 k-1,48 k-9,48 k-17,48 k-25, \ldots, 40 k+7, \\
48 k-3,48 k-11,48 k-19,48 k-27, \ldots, 40 k+5
\end{array}\right\} \\
& =\left\{\begin{array}{c}
1,3,5,7,9,13,15,17,19,21,23,25,27,29, \ldots, 16 k-7,16 k-5,16 k-3,16 k-1 \\
16 k+1,16 k+3,6 k+5,16 k+7, \ldots, 24 k-31,24 k-29,24 k-27,24 k-25, \\
24 k-23,24 k-21,24 k-19,24 k-17,24 k-15,24 k-13,24 k-11,24 k-9, \\
24 k-7,24 k-5,24 k-3,24 k-1 \\
24 k+1,24 k+3,24 k+5,24 k+7,24 k+9,24 k+11,24 k+13,24 k+15, \\
24 k+31, \ldots, 40 k-7,40 k-5,40 k-3,40 k-1, \\
40 k+1,40 k+3,40 k+5,40 k+7, \ldots, 48 k-31,48 k-29,48 k-27, \\
48 k-25,48 k-23,48 k-21,48 k-19,48 k-17,48 k-15,48 k-13, \\
48 k-11,48 k-9,48 k-7,48 k-5,48 k-3,48 k-1
\end{array}\right\}
\end{aligned}
$$

$=\{1,3,5,7, \ldots, 48 k-1\}$.

Terlihat bahwa fungsi $f^{*}$ memberikan label yang berbeda pada setiap busur dan $f^{*}\left(E\left(k L_{3,3} \cup\right.\right.$ $\left.\left.k L_{3,3}\right)\right)=\{1,3,5,7, \ldots, 48 k-1\}$ sehingga fungsi pelabelan busur $f^{*}$ memenuhi sifat pemetaan bijektif. Telah ditunjukkan bahwa fungsi pelabelan simpul $f$ memenuhi pemetaan injektif sedemikian sehingga menginduksi fungsi pelabelan busur $f^{*}$ yang bijektif. Akibatnya gabungan graf ular jaring $k L_{3,3} \cup k L_{3,3}$ dengan $k \geq 1$ adalah graf harmonis ganjil

\section{Contoh 3.6}

Berikut pada Gambar 4 diberikan contoh pelabelan harmonis ganjil dari gabungan graf ular jaring $7 L_{3,3} \cup 7 L_{3,3}$
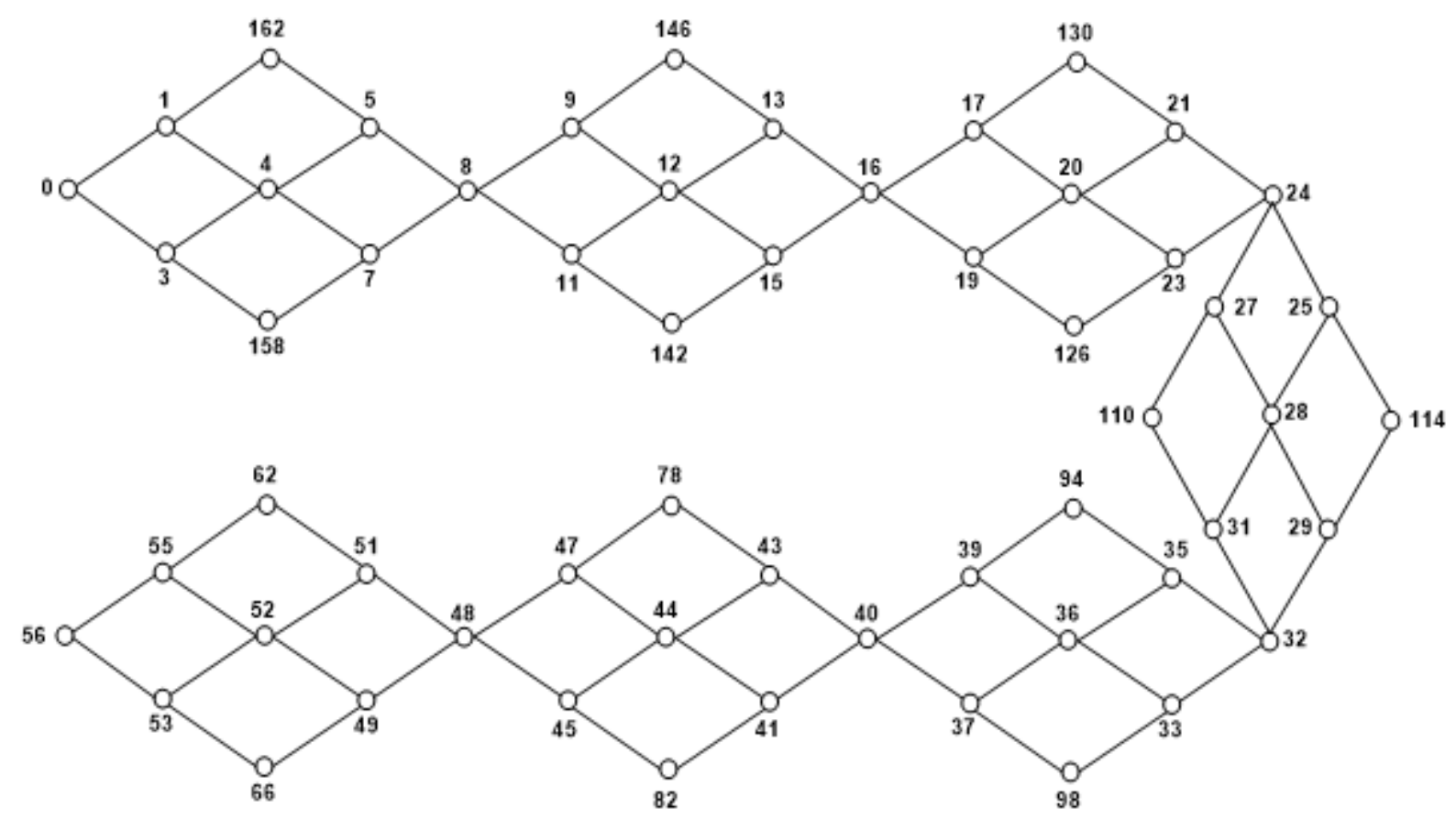

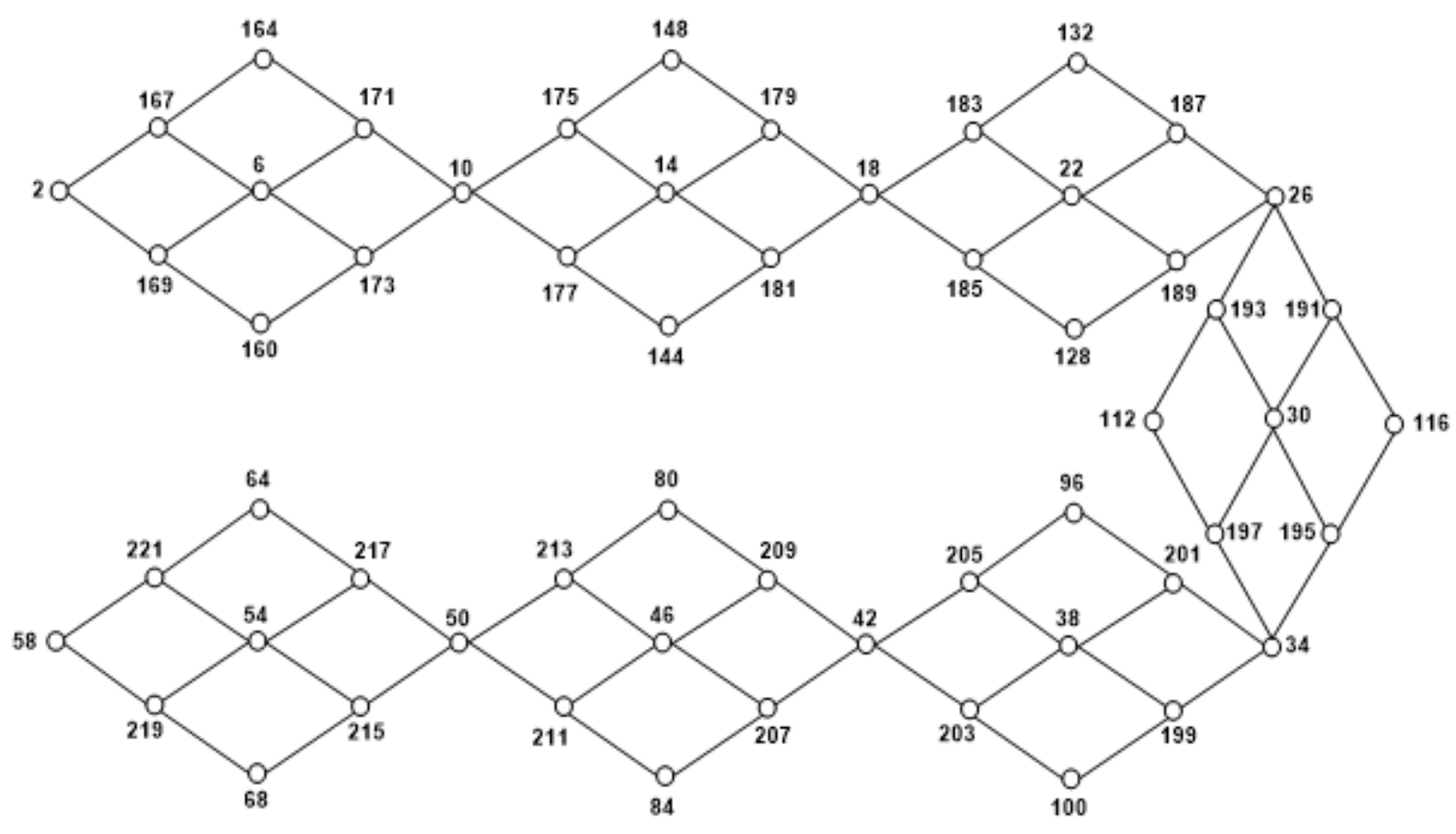

$$
7\left(L_{3,3}\right) \cup 7\left(L_{3,3}\right)
$$

Gambar 4 Pelabelan harmonis ganjil pada gabungan graf ular jaring $7 L_{3,3} \cup 7 L_{3,3}$

\section{Penutup}

Pada makalah ini telah didapatkan kelas graf baru yang merupakan hasil operasi cartesian product yang memenuhi sifat-sifat pelabelan harmonis ganjil yaitu graf ular jaring $k L_{3,3}$ dengan $k \geq 1$ dan gabungan graf ular jaring $k L_{3,3} \cup k L_{3,3}$ dengan $k \geq$ 1 sedemikian sehingga diperoleh keluarga baru dari graf harmonis ganjil. Hasil penelitian ini bisa dilanjutkan untuk graf ular jaring $k L_{m, n}$ dengan $m \geq 1, n \geq 1, k \geq 1$ dan gabungannya $k L_{m, n} \cup$ $k L_{m, n}$ dengan $m \geq 1, n \geq 1, k \geq 1$.

\section{Ucapan Terima Kasih}

Penulis mengucapkan terima kasih kepada Ristek Dikti yang telah memberi dukungan financial terhadap penelitian ini melalui Hibah Penelitian Dosen Pemula (PDP) tahun 2017.

\section{Referensi}

[1] Abdel-Aal, M. E. New Families of Odd Harmonious Graphs. International Journal of Soft Computing, Mathematics and Control, 3(1), (2014) 1-13.

[2] Alyani, F., Firmansah, F., Giyarti, W., dan Sugeng, K. A. The Odd Harmonious Labeling of kCn-Snake Graphs for Spesific Values of n, that is, for $\mathrm{n}=4$ and $\mathrm{n}=8$. Proceeding IndoMS International Conference on Mathemathics and Its Applications, UGM dan IndoMS. (2013) 225-230. 6-7 November, Yogyakarta.

[3] Firmansah, F., dan Sugeng, K. A. Pelabelan Harmonis Ganjil pada Graf Kincir Angin Belanda dan Gabungan Graf Kincir Angin Belanda. Magistra, No 94 Th. XXVII, ISSN 0215-9511, (2015) 56-92. 
[4] Firmansah, F. 2016. Pelabelan Harmonis Ganjil pada Gabungan Graf Ular dan Graf Ular Berlipat. Proceeding Konferensi Nasional Matematika dan Pembelajarannya (KNPMP 1) UMS. (2016) 809-818. 12 Maret, Surakarta.

[5] Firmansah, F. dan Syaifuddin, M. W. Pelabelan Harmonis Ganjil pada Graf Kincir Angin Double Quadrilateral. Proceeding Seminar Nasional Matematika dan Pendidikan Matematika, FKIP UNY, (2016) 53-58. 5 November, Yogyakarta.

[6] Firmansah, F. dan Yuwono, M. R. Odd Harmonius Labeling on Pleated of the Dutch Windmill Graphs. Cauchy - Jurnal Matematika Murni dan Aplikasi, 4(4). (2017) 161-166. p-ISSN: 2086-0382, e-ISSN: 24773344.

[7] Jeyanthi, P. dan Philo, S. Odd Harmonious Labeling of Some Cycle Related Graphs. Proyecciones Journal of Matematics, 35(1). (2016) 85-98.

[8] Jeyanthi, P., Philo, S. dan Sugeng, K.A. Odd Harmonious Labeling of Some New Families of Graphs. SUT Journal of Mathematics. 51(2). (2015) 53-65.

[9] Gallian, J. A. A Dynamic Survey of Graph Labeling. The Electronic Journal of Combinatorics, 18. (2016) \#DS6.

[10] Liang, Z., dan Bai, Z. On The Odd Harmonious Graphs with Applications, $J$. Appl. Math. Comput., 29, (2009) 105-116.

[11] Saputri, G. A., Sugeng, K. A., dan Froncek, D. The Odd Harmonious Labeling of Dumbbell and Generalized Prims Graphs, AKCE Int, J. Graphs Comb., 10(2), (2013) 221-228.

[12] Vaidya, S. K., dan Shah, N. H. Some New Odd Harmonious Graphs. International Journal of Mathematics and Soft Computing, 1(1), (2011) 9-16. 